\title{
A systematic review and meta-analysis of published randomized controlled trials of combination of clopidogrel and aspirin in transient ischemic attack or minor stroke
}

\author{
XINGJIAN ZHOU $^{1 *}$, JING TIAN $^{1 *}$, MING ZHEN ZHU ${ }^{1}$ and COLIN K. HE $^{2}$ \\ ${ }^{1}$ Department of Endocrinology, Xiangyang No. 1 People's Hospital, Hubei University of Medicine, \\ Xiangyang, Hubei 441000, P.R. China; ${ }^{2}$ Orient Health Care, StegoTech LLC, King of Prussia, PA 19406, USA
}

Received November 16, 2016; Accepted April 28, 2017

DOI: $10.3892 /$ etm.2017.4459

\begin{abstract}
The use of antiplatelet agents in patients with ischemic stroke is recommended. In this study, we compared the efficacy and safety of the treatment of clopidogrel plus aspirin (ASA) and that of ASA alone in patients with mild stroke/transient ischemic attack (TIA). Randomized controlled trial (RCT) studies of Clop + ASA vs. ASA therapy in the patients with minor stroke/TIA were identified by electronic bibliographic searches. The primary result was recurrent stroke, while myocardial infarction (MI) as well as vascular mortalities were the secondary result, and major hemorrhagic events were the safety result. A comparative analysis of binary outcomes was performed on the treatment groups, with the employment of fixed effect models and the measurement of risk ratios (95\% CI). Five RCT studies involving 9,527 patients were included. Compared with the group with ASA treatment, there was significant reduction in the incidence of recurrent stroke in the group with Clop + ASA ( $R R=0.76,95 \% \mathrm{CI}=0.67-0.87$, $\mathrm{P}<0.0001)$, and there was no significant increase in the incidence of vascular mortalities and MI $(\mathrm{R} R=1.08$, 95\% $\mathrm{CI}=0.83-1.41, \mathrm{P}=0.56)$ and no significant change in major hemorrhagic events $(\mathrm{RR}=1.55,95 \% \mathrm{CI}=0.72-3.36$, $\mathrm{P}=0.26$ ). Therefore, the treatment with Clop + ASA seems safe as well as effective for decreasing stroke recurrence. In addition, this is related to a statistically insignificant trend in increasing vascular mortalities, MI, and primary hemorrhagic events. These findings need to be confirmed in prospective studies.
\end{abstract}

Correspondence to: Dr Colin K. He, Orient Health Care, StegoTech LLC, 422 Lynrose Court, King of Prussia, PA 19406, USA

E-mail:kqkuse@163.com

*Contributed equally

Key words: aspirin, antiplatelet therapy, clopidogrel, stroke

\section{Introduction}

In June 2009, the concept of transient ischemic attack (TIA) was newly defined by the American Heart Association/American Stroke Association, as brief episodes of neurologic dysfunction that are induced by ischemia of a focal brain region, or retina, spinal cord, without causing any acute infarction for the body 1). According to previous studies, minor stroke has been defined according to various criteria. Clinical studies on minor stroke use $<3$ of the current National Institutes of Health Stroke Scale (NIHSS) score as a common criterion. In China, there are 3 million new patients with onset stroke each year, of which $30 \%$ are minor strokes $(2,3)$. In addition, 2 million individuals are diagnosed with TIA $(1,4)$. TIA/minor stroke patients bear high-risk recurrent and disabling cerebral stroke at an early stage. Studies have demonstrated that stroke has a recurrence rate of 10-20\% within 3 months and usually occurs within the first 2 days after the initial onset $(5,6)$. Therefore, early intervention is critical for TIA/minor stroke patients.

Antiplatelets taken at an early stage can reduce the risk of ischemic events. The latest American guidelines suggest taking an initial oral dose of $325 \mathrm{mg}$ of aspirin (ASA) (class I; level of evidence A within 24-48 h. However, the efficacy of clopidogrel (Clop) requires further study (class IIb; level of evidence C) (7). In 2010, Hankey and Eikelboom metaanalysis demonstrated that treatment with Clop + ASA was immediately more effective than treatment with ASA alone, and the risk of bleeding is not significantly increased when acute ischemic stroke and TIA patients are at the highest risk of recurrent strokes (8).

Based on the Cochrane system, this study aimed to explore the efficacy of Clop + ASA in large scale clinical studies published in recent years for preventing major ischemic vascular events and to characterize the associated risk of potential hemorrhagic events when taken early by TIA/minor stroke patients with a high-risk stroke recurrence and low-risk bleeding.

\section{Materials and methods}

Experimental procedures. As a systematic review and meta-analysis of published research, no patient consent 
or ethical approval was required for the study. The design and implementation of this study conformed to the criteria of Preferred Reporting Items for Systematic Reviews and Meta-Analyses (PRISMA) (9).

Eligibility criteria. Research that met the requirements below was included in the study: i) the study design of the reviewed research is a randomized controlled trial (RCT); ii) patients: TIA/minor stroke patients aged $\geq 18$; iii) interventions: the trial group received Clop + ASA, while the control group received ASA alone; and iv) outcomes: incidence of recurrent stroke, vascular mortalities, myocardial infarction (MI), and major hemorrhagic events.

Exclusion criteria for the study were: i) unpublished studies; ii) studies without assessment of the measurement indexes; iii) studies with missing data for which statistical analysis cannot be performed; and iv) repeatedly published studies or general reviews.

Search strategy. Databases listed as below were searched independently by two researchers J.T. and M.Z.Z. (PubMed, Cochrane, EMBase, Medline, and Web of Science) to confirm eligible studies. The following keywords were used: aspirin, antiplatelet therapy, cerebral ischemia, clopidogrel, minor stroke, randomized controlled trial and transient ischemic attack. The screening study was conducted on the screened full-text in order to evaluate additional possible eligible trials.

The studies were independently screened and verified in accordance with the inclusion as well as exclusion criteria. Titles and abstracts were first reviewed to exclude studies that did not comply with the inclusion criteria. For the studies that were potentially eligible, a second screening was conducted by reading the whole text. Any disagreement was solved by a third reviewer $(\mathrm{CKH})$ through consultation.

Data extraction and measurement of outcome. A piloted extraction datasheet was employed with the following information covered: research title, number of patients, average age of patients, percentage of male patients, received drug dose of the trial group, received drug dose of the control group, time interval from onset of symptoms to entering studies, treatment duration, and percentage of patients lost to follow-up.

The investigators extracted all data from the reports. Any disagreement was settled through consultation. When necessary, we contacted the corresponding authors by e-mail to gain accurate data. The primary outcome encompassed recurrent stroke, and MI and vascular mortalities were the secondary outcomes, and major hemorrhagic events were for the safety outcome.

Evaluation of risk of bias and the assessment of the quality of included research. With reference to version 5.1.0 of the Cochrane Handbook for Systematic Reviews of Interventions, risk of bias was assessed for this study (10). After reviewing all included articles, a level of unclear, low or high was assigned to the following areas: i) random sequence generation; ii) blinding of personnel and participants; iii) allocation concealment; iv) blinding of outcome assessment; v) selective reporting; and vi) incomplete outcome data, and other sources of bias.

The assessment of the quality of the research was conducted using the GRADE form (11). Evidence was divided into the following levels: high quality (our confidence in the estimated effect will unlikely be changed by further research), moderate quality (our confidence in the estimated effect is likely to be changed by further research), low quality (our confidence in the estimated effect is very likely to be changed by further research), very low quality of the evidence (we remain quite uncertain about the estimated effect).

Statistical analysis. The relative risk was estimated with a $95 \%$ confidence interval for binary outcomes. I2 was used in tests for homogeneity. I 2 above $50 \%$ suggested significant heterogeneity and that the random effects model was expected to be employed, and if not the fixed effect model was to be employed (12). When significant heterogeneity was present, sensitivity analysis was used to identify potential sources of heterogeneity. If a study was included and the total RR changed substantially, this suggested that the study had a large bias and the result should be interpreted carefully. Based on the sample size, cumulative meta-analysis was used to evaluate the influence of citing studies with large sample size on the incorporated result. The Egger's test and Egger's funnel plot were performed for assessing any publication bias in the studies included (13). Results were assumed statistically significant when $\mathrm{P}<0.05$. RevMan 5.2 and R 3.1.1 were used to perform the statistical analyses.

\section{Results}

Selection of studies and their characteristics. The retrieval and screening results of this study are shown in Fig. 1. A total of 168 relevant potential studies were obtained through a preliminary screening, while 131 studies were excluded by reading of their titles and abstracts. The full contents of the remaining 37 studies were reviewed, with 32 of them eliminated (27 did not conform to the criteria, 3 were systematic reviews, and 2 were absent of data). Five RCT studies conforming to the criteria were selected for the meta-analysis.

Main characteristics of the 5 RCT studies used for the meta-analysis are shown in Table I. The studies were published from 2005 to 2014; 3 were carried out in Canada, 1 in China, and 1 in the UK. The sample sizes ranged from 107 to 5,170 (the total sample size was 9,527 cases). The average age of patients in these 5 RCT studies was 62-68 years, with a male predominance (53-69\%). The duration from onset of symptoms to inclusion into studies (start of treatment) ranged from $24 \mathrm{~h}$ to 3 months (three articles in $\leq 72 \mathrm{~h}$; two articles within 3 months). The treatment durations ranged from 7 days to 3.5 years (three articles in $\leq 3$ months; two articles in $\leq 3.5$ years).

Risk of bias and evidence level. The risks of bias of the five aforementioned RCT studies are shown in Fig. 2. Randomized sequence generation was unclear in ASA failure and Clop + ASA for reduction of emboli in symptomatic carotid stenosis because these studies only described randomization instead of the process of random sequence generation. The remaining studies were assumed to have low risk of bias. 
Table I. Design features and baseline characteristics of participants.

\begin{tabular}{|c|c|c|c|c|c|c|c|c|c|}
\hline Study name & No. & $\begin{array}{l}\text { Mean } \\
\text { age } \\
\text { (years) }\end{array}$ & $\begin{array}{c}\text { Men } \\
(\%)\end{array}$ & $\begin{array}{l}\text { Treatment } \\
\text { group and } \\
\text { dose }\end{array}$ & $\begin{array}{l}\text { Comparison } \\
\text { group and } \\
\text { dose }\end{array}$ & $\begin{array}{l}\text { Treatment } \\
\text { onset }\end{array}$ & $\begin{array}{l}\text { Treatment } \\
\text { duration }\end{array}$ & $\begin{array}{l}\text { Lost to } \\
\text { follow-up } \\
\quad(\%)\end{array}$ & Refs. \\
\hline CHANCE & 5,170 & 62 & 66 & $\begin{array}{l}\text { Asp ( } 76-300 \mathrm{mg} \text { load } \\
\text { then } 75 \mathrm{mg} \text { od first } 12 \text { days) } \\
\text { + Clop ( } 300 \mathrm{mg} \text { load } \\
\text { then } 75 \mathrm{mg} \mathrm{od})\end{array}$ & $\begin{array}{l}\text { Asp }(76-300 \mathrm{mg} \\
\text { load then } 75 \mathrm{mg} \text { od) }\end{array}$ & $72 \mathrm{~h}$ & 90 days & 0.7 & (14) \\
\hline PASTER & 392 & 68 & 53 & $\begin{array}{l}\text { Asp }(81 \mathrm{mg} \mathrm{od}) \\
+ \text { Clop }(300 \mathrm{mg} \text { load } \\
\text { then } 75 \mathrm{mg} \text { od })\end{array}$ & Asp (81 mg od) & $24 \mathrm{~h}$ & 90 days & 1.79 & $(15)$ \\
\hline CARESS & 197 & 65 & 69 & $\begin{array}{l}\text { Asp ( } 75 \mathrm{mg} \text { load) } \\
+ \text { Clop ( } 300 \mathrm{mg} \text { load } \\
\text { then } 75 \mathrm{mg} \text { od })\end{array}$ & Asp (75 mg od) & $72 \mathrm{~h}$ & 7 days & None & (16) \\
\hline Failure & 888 & 66 & 65 & $\begin{array}{l}\text { Asp (325 mg od) } \\
+ \text { Clop (75 mg od) }\end{array}$ & Asp (325 mg od) & 150 days & 3.5 years & NR & (17) \\
\hline SPS3 & 3,020 & 63 & 65 & $\begin{array}{l}\text { Asp (325 mg od) } \\
\text { + Clop (75 mg od) }\end{array}$ & Asp (325 mg od) & 150 days & 3.5 years & NR & (18) \\
\hline
\end{tabular}

od, once daily; NR, not reported.

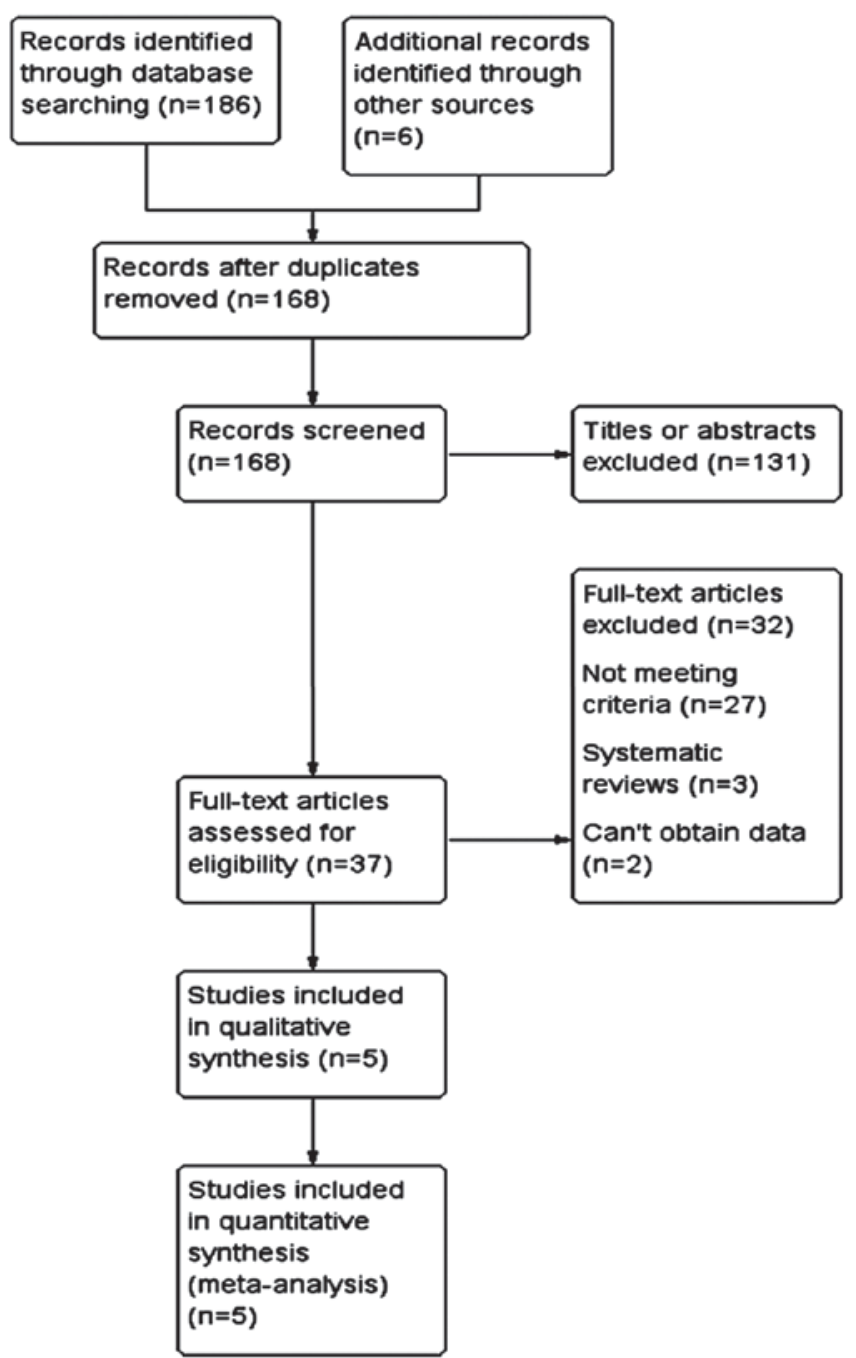

Figure 1. Flow chart of literature retrieval and screening.

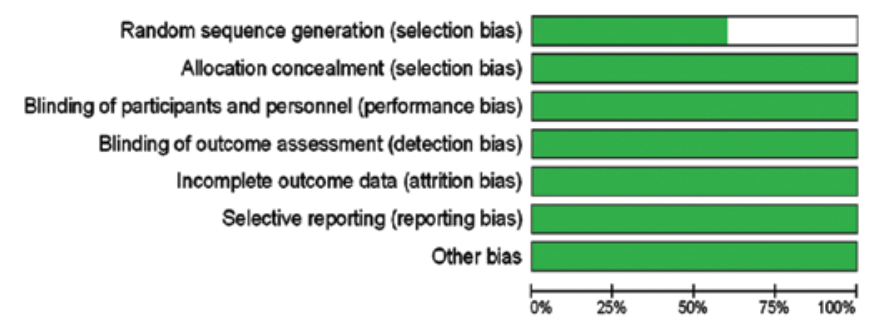

Low risk of bias $\square$ Unclear risk of bias $\square$ High risk of bias

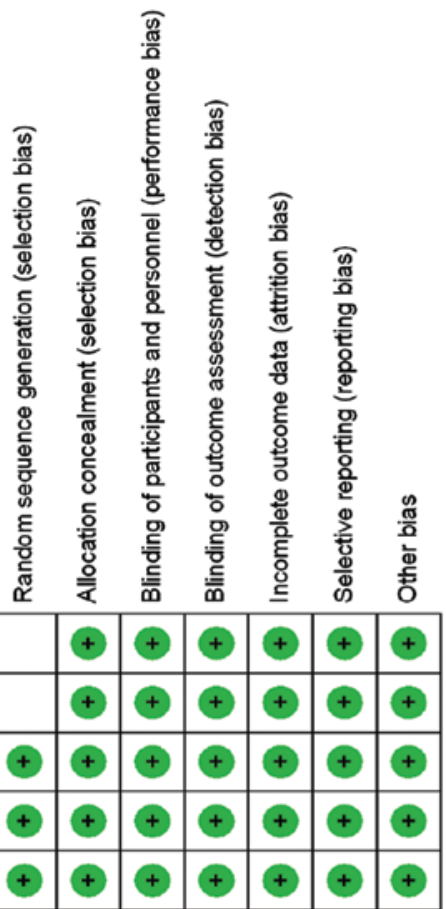

Figure 2. Cochrance chart of risk of bias assessment. 
Table II. Clop + ASA compared with ASA for TIA/minor stroke patients.

\begin{tabular}{|c|c|c|c|c|c|}
\hline \multirow[b]{2}{*}{ Outcomes } & \multicolumn{2}{|c|}{$\begin{array}{l}\text { Illustrative comparative risk } \\
\qquad(95 \% \mathrm{CI})\end{array}$} & \multirow[b]{2}{*}{$\begin{array}{l}\text { Relative effect } \\
\quad(95 \% \mathrm{CI})\end{array}$} & \multirow[b]{2}{*}{$\begin{array}{l}\text { No. of participants } \\
\text { (studies) }\end{array}$} & \multirow[b]{2}{*}{$\begin{array}{l}\text { Quality of evidence } \\
\text { (GRADE) }\end{array}$} \\
\hline & $\begin{array}{l}\text { Assumed risk } \\
\text { ASA }\end{array}$ & $\begin{array}{c}\text { Corresponding risk } \\
\text { Clop + ASA }\end{array}$ & & & \\
\hline \multirow{4}{*}{$\begin{array}{l}\text { MI and vascular } \\
\text { mortality }\end{array}$} & \multicolumn{2}{|c|}{ Study population } & & & \\
\hline & $21 / 1,000$ & $\begin{array}{c}23 / 1,000 \\
(18-30)\end{array}$ & $\begin{array}{c}\mathrm{RR}=1.08 \\
(0.83-1.41)\end{array}$ & $\begin{array}{c}9,328 \\
\text { (5 studies) }\end{array}$ & $\begin{array}{l}++++ \\
\text { High }\end{array}$ \\
\hline & \multicolumn{2}{|c|}{ Moderate } & & & \\
\hline & $38 / 1,000$ & $\begin{array}{c}41 / 1,000 \\
(32-54)\end{array}$ & & & \\
\hline \multirow[t]{4}{*}{ Stroke recurrence } & \multicolumn{2}{|c|}{ Study population } & & & \\
\hline & $110 / 1,000$ & $\begin{array}{c}84 / 1,000 \\
(74-96)\end{array}$ & $\begin{array}{c}\mathrm{RR}=0.76 \\
(0.67-0.87)\end{array}$ & $\begin{array}{c}9,328 \\
\text { (5 studies) }\end{array}$ & $\begin{array}{l}++++ \\
\text { High }\end{array}$ \\
\hline & \multicolumn{2}{|c|}{ Moderate } & & & \\
\hline & $117 / 1,000$ & $\begin{array}{l}89 / 1,000 \\
(78-102)\end{array}$ & & & \\
\hline \multirow[t]{4}{*}{ Major hemorrhage } & \multicolumn{2}{|c|}{ Study population } & & & \\
\hline & $2 / 1,000$ & $\begin{array}{c}3 / 1,000 \\
(2-7)\end{array}$ & $\begin{array}{c}\mathrm{RR}=1.55 \\
(0.72-3.36)\end{array}$ & $\begin{array}{c}9,527 \\
\text { (5 studies) }\end{array}$ & $\begin{array}{c}+++- \\
\text { Moderate }\end{array}$ \\
\hline & \multicolumn{2}{|c|}{ Moderate } & & & \\
\hline & $2 / 1,000$ & $\begin{array}{c}3 / 1,000 \\
(1-7)\end{array}$ & & & \\
\hline
\end{tabular}

Clop, clopidogrel; ASA, aspirin; TIA, transient ischemic attack; MI, myocardial infarction.

GRADE was employed to evaluate the quality of evidence and recommended level (Table II). The results showed that recurrent strokes, MIs, and vascular mortalities were high quality evidence, while major hemorrhagic events were moderate quality.

Major outcome: recurrent stroke. The incidence of recurrent stroke in the group of Clop + ASA was $8.38 \%$, while the incidence in the ASA group was $10.99 \%$. Compared with ASA, Clop + ASA resulted in a significantly lower incidence of recurrent stroke of the group with TIA/minor stroke $(\mathrm{RR}=0.76$, 95\% CI=0.67-0.87, P<0.0001, Fig. 3A). No heterogeneity was present between the trial and control groups (I2=19\%). Egger's regression line (Fig. 3B) was made, and a null hypothesis was tested whether the regression line intercepted 0 or not. No bias was suggested with the use of Egger's test ( $\mathrm{P}$ for bias turned out 0.72 )

Cumulative meta-analysis was performed based on sample sizes (Fig. 4). The treatment effect was initially large, although after adding studies with large sample sizes, the confidence interval narrowed, and the treatment effect became smaller and stable, albeit the treatment effect was still highly significant $(\mathrm{P}<0.0001)$. This analysis indicated that studies with small sample sizes may overestimate the effect of Clop + ASA in lowering recurrent stroke.

Secondary outcome: myocardial infarction and vascular mortality. The incidence of MI and vascular mortalities was $2.33 \%$ in the Clop + ASA group and $2.13 \%$ in the ASA group. Compared with ASA, the incidence of MI as well as vascular mortalities was not significantly increased in the group with Clop + ASA $(\mathrm{RR}=1.08,95 \% \mathrm{CI}=0.83-1.41$, $\mathrm{P}=0.56$, Fig. 5A). No heterogeneity was present between the trial and control groups $(\mathrm{I} 2=0 \%)$. Egger's regression line (Fig. 5B) was constructed and did not show evidence of any publication bias with the use of Egger's test (P-value for bias was 0.887).

Cumulative meta-analysis was performed based on sample sizes (Fig. 6). The total RR was initially unstable as it fluctuated between values of $>1.0$ and $<1.0$. However, after accumulating additional studies, the total RR became stable and the confidence interval became narrow. This analysis suggested that combination therapy does not increase the incidence of vascular mortalities. 


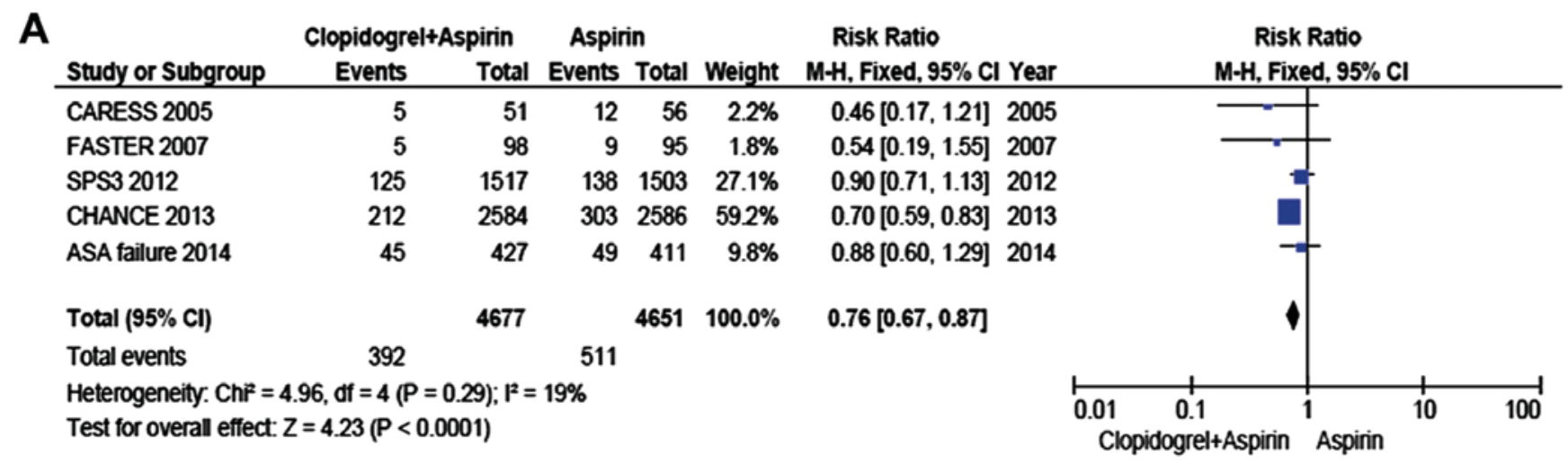

B

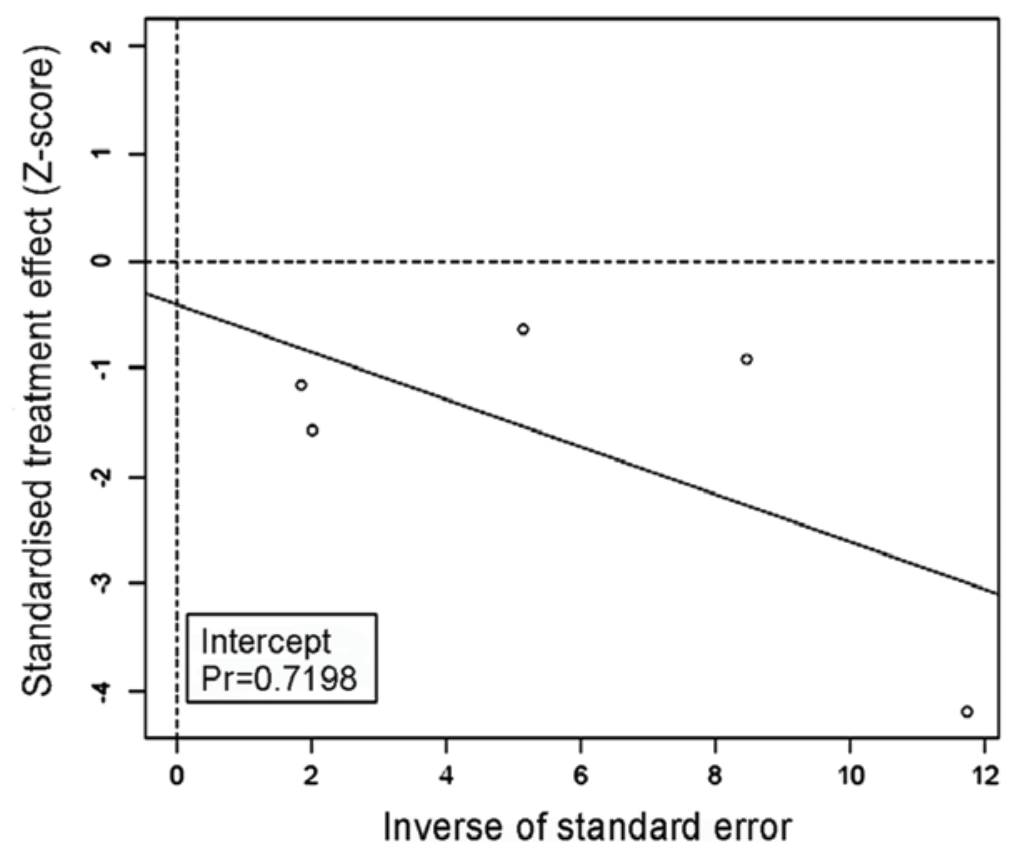

Figure 3. Meta-analysis of recurrent stroke for Clop + ASA compared with ASA. (A) Forest plot of recurrent stroke in two groups; (B) Egger's regression line of recurrent stroke for Clop + ASA compared with ASA. Clop, clopidogrel; ASA, aspirin.

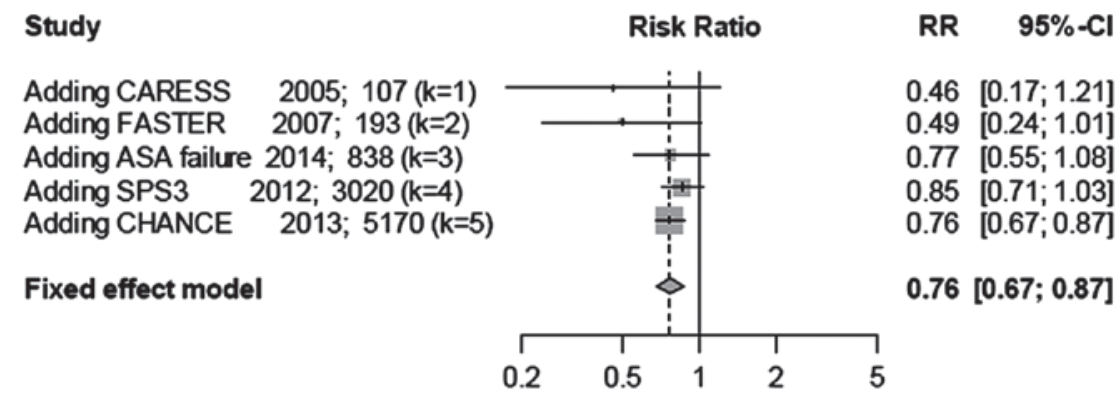

Figure 4. Accumulative meta-analysis of recurrent stroke for Clop + ASA compared with ASA. Clop, clopidogrel; ASA, aspirin.

Safety outcome. The incidence of major hemorrhagic events was $0.33 \%$ in the Clop + ASA group and $0.21 \%$ in the ASA group. Compared with ASA, the incidence of hemorrhagic events was not increased in the group of Clop + ASA (RR=1.55, 95\% CI=0.72-3.36, $\mathrm{P}=0.26$, Fig. 7A). No heterogeneity was present between the trial and control groups (I2=0\%). Egger's regression line (Fig. 7B) was plotted and the Egger's test did not suggest any publication bias (P-value for bias was 0.9723).

Cumulative meta-analysis was performed based on sample sizes (Fig. 8). The treatment effect was large at the beginning, although after adding studies with large sample sizes, the confidence interval narrowed, and the treatment effect became smaller and stable. This analysis suggested that 
A

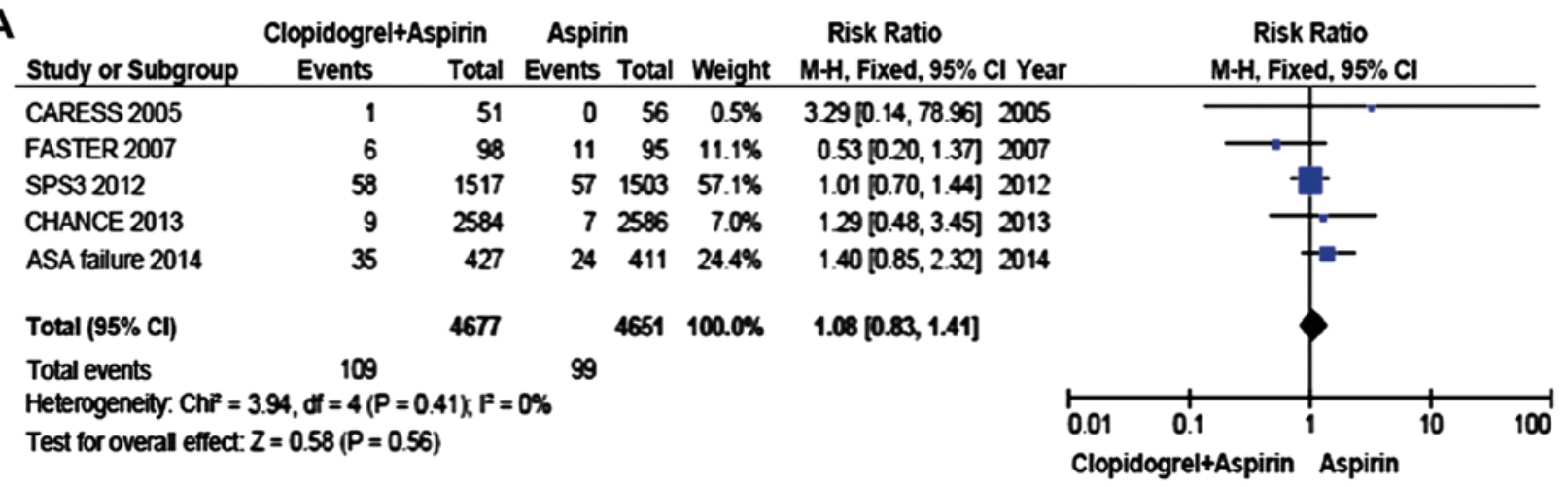

B

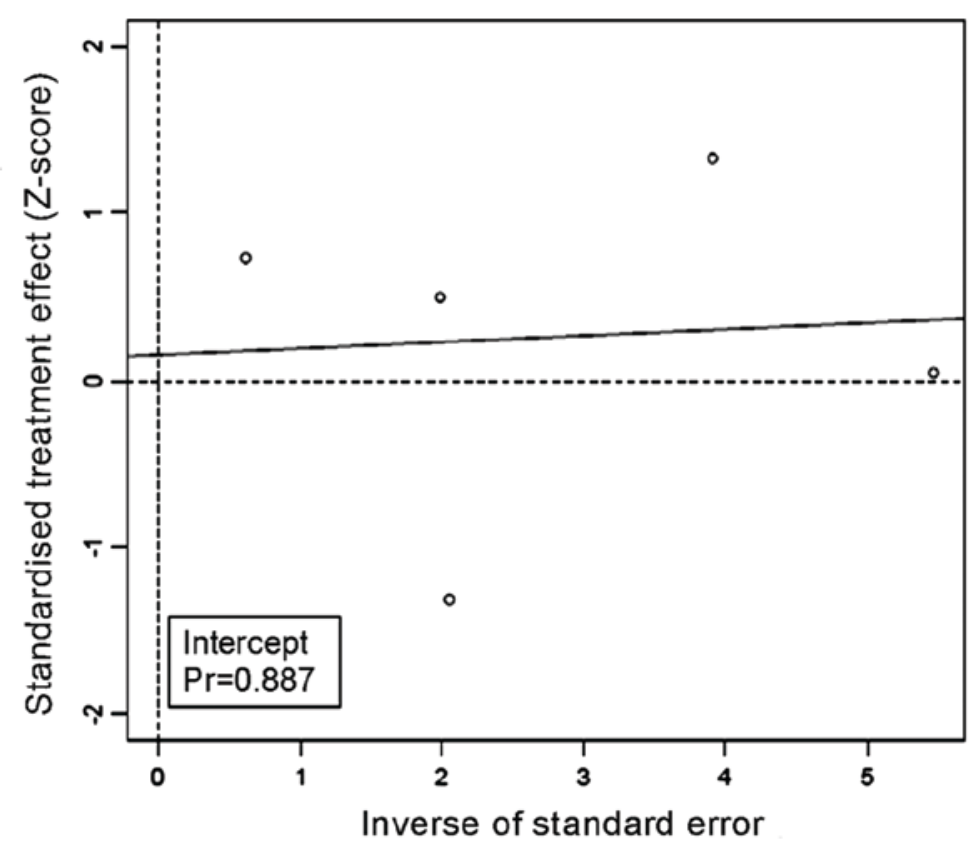

Figure 5. Meta-analysis of the incidence of MI and vascular mortalities for Clop + ASA compared with ASA. (A) Forest plot of the incidence of MI and vascular mortalities in two groups; (B) Egger's regression line of MI and vascular mortality for Clop + ASA compared with ASA. MI, myocardial infarction; Clop, clopidogrel; ASA, aspirin.

Study

\begin{tabular}{|c|c|}
\hline $\begin{array}{l}\text { Adding CARESS } \\
\text { Adding FASTER } \\
\text { Adding ASA failure }\end{array}$ & $\begin{array}{c}2005 ; 107(k=1) \\
2007 ; 193(k=2) \\
2014 ; 838(k=3)\end{array}$ \\
\hline $\begin{array}{l}\text { Adding SPS3 } \\
\text { Adding CHANCE }\end{array}$ & $\begin{array}{l}2012 ; 3020(k=4) \\
2013 ; 5170(k=5)\end{array}$ \\
\hline
\end{tabular}

Fixed effect model

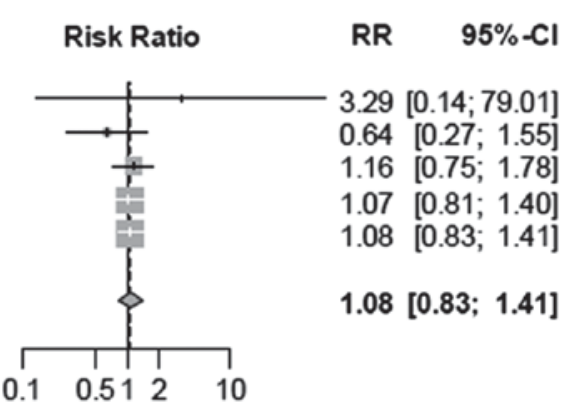

Figure 6. Accumulative meta-analysis of the incidence of MI and vascular mortalities for Clop + ASA compared with ASA. MI, myocardial infarction; Clop, clopidogrel; ASA, aspirin.

combination therapy does not increase the incidence of major hemorrhagic events.

\section{Discussion}

Of two relevant meta-analyses published in 2012, one showed that dual antiplatelet therapy may lower the incidence of recurrent stroke and vascular events along with total mortalities, without increasing the risk of hemorrhage when compared with mono-antiplatelet therapy for stroke/TIA patients (19). However, another meta-analysis showed the opposite result, namely patients with vascular disease taking Clop + ASA may experience an increased risk of fatal hemorrhage (20). Therefore, the effects of the two antiplatelet drugs when used in 
A

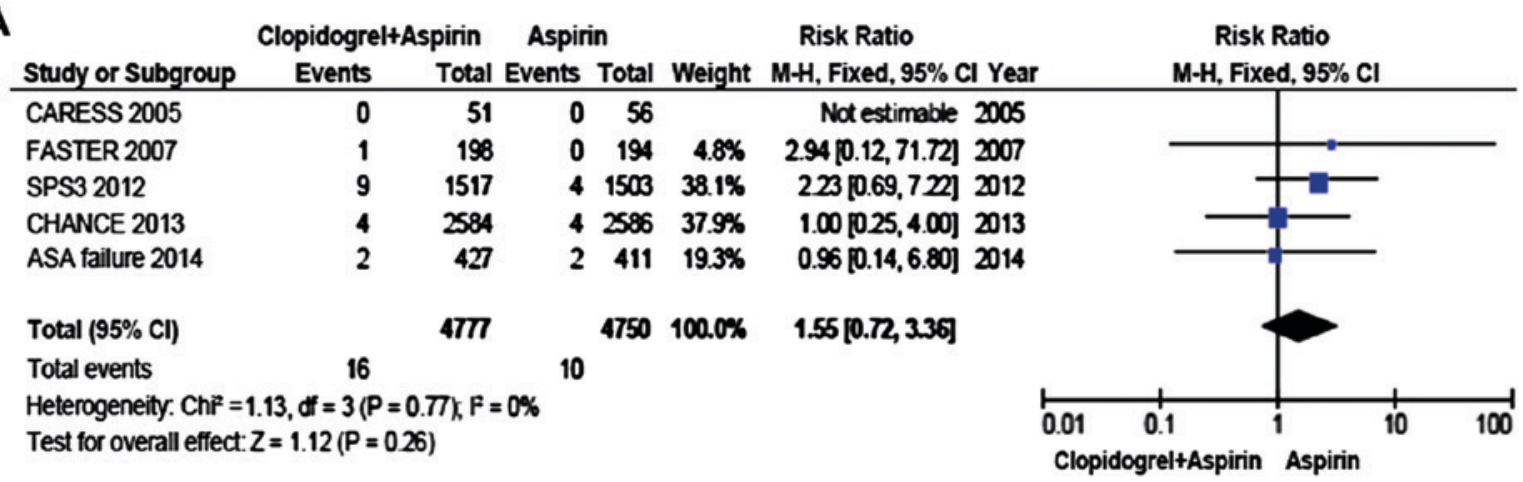

B

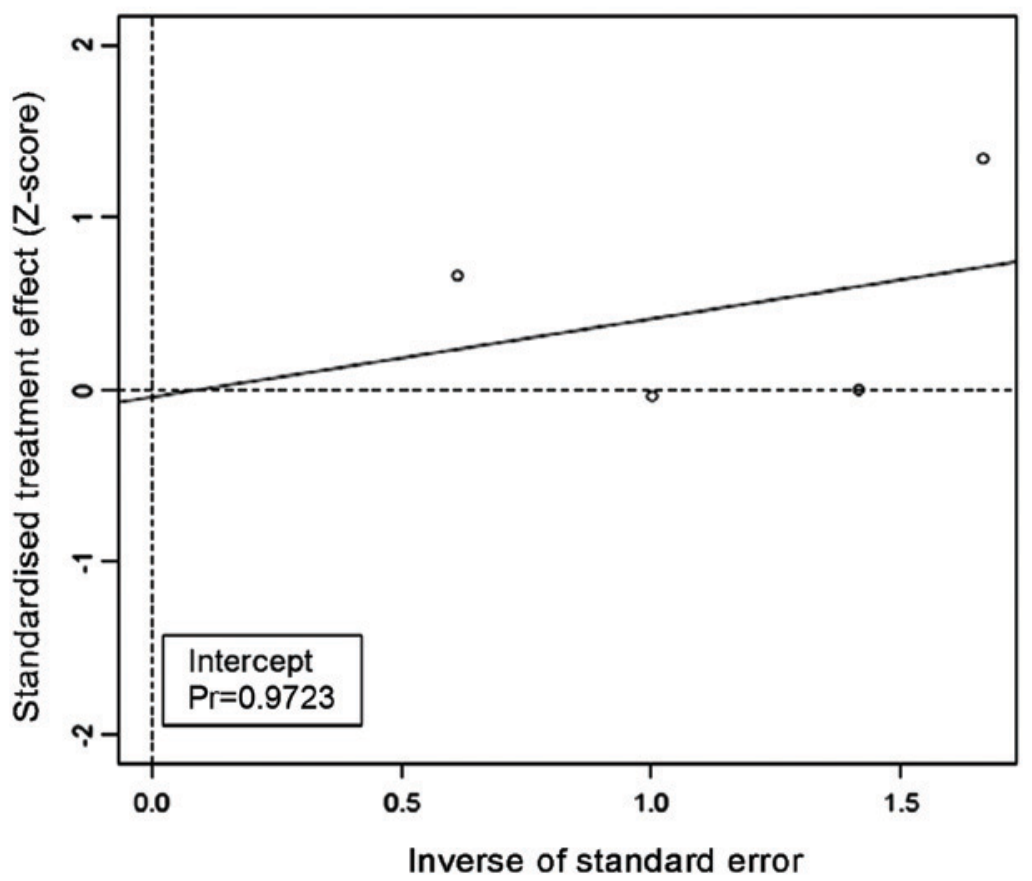

Figure 7. Meta-analysis of the incidence of major hemorrhagic events for Clop + ASA compared with ASA. (A) Forest plot of the incidence of major hemorrhagic events in two groups. (B) Egger's regression line of major hemorrhagic events for Clop + ASA compared with ASA. Clop, clopidogrel; ASA, aspirin.

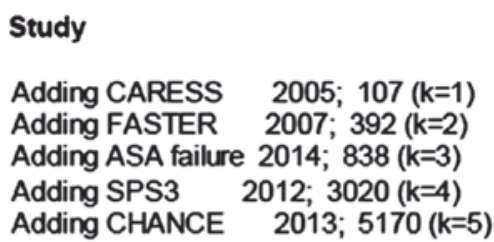

Fixed effect model

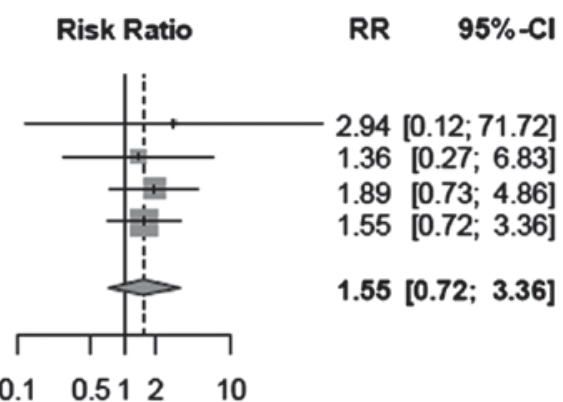

Figure 8. Accumulative meta-analysis of the incidence of major hemorrhagic events for Clop + ASA compared with ASA. Clop, clopidogrel; ASA, aspirin. combination require further study. Since a significant amount of research results have been reported in recent years, we evaluated the safety and efficacy of treatment with Clop + ASA compared with ASA alone for TIA/minor stroke patients.

The primary and secondary outcomes of this study show that the incidence of recurrent stroke can be significantly decreased with the treatment of Clop + ASA ( RR $=0.76$, $95 \% \mathrm{CI}=0.67-0.87, \mathrm{P}<0.0001)$, and $\mathrm{MI}$ and vascular mortalities is not significantly changed by such treatment $(\mathrm{RR}=1.08$, 95\% CI=0.83-1.41, $\mathrm{P}=0.56$ ). These findings are inconsistent with the results of previous meta-analyses $(19,20)$. Transcranial Doppler ultrasound recordings provided supportive evidence in these studies as the number of microembolic signals is proportional to recurrent stroke and risk of other vascular events. Both CARESS (16) and Clop + ASA for infarction reduction (CLAIR) (21) demonstrate that compared with 
ASA alone, combination therapy of Clop + ASA significantly reduces microembolic signals. Therefore, the risks of recurrent stroke as well as other vascular events are reduced with combination therapy as well.

The safety outcomes show that Clop + ASA does not result in an increase in the risk of major hemorrhagic events ( $\mathrm{RR}=1.55,95 \% \mathrm{CI}=0.72-3.36, \mathrm{P}=0.26)$. Possible reasons for the inconsistency with the results from other studies include: i) selection of patients: the population in this study were TIA/minor stroke patients who suffered from a high risk of recurrent ischemic events at an early stage and were at low risk of hemorrhages. However, several other studies included other types of stroke patients or patients with other vascular pathologies. Thus, the potential risks of bleeding in patients from these studies were inherently higher. ii) Drug dosage and duration of treatment: in the SPS3 study, the drug dosage was $325 \mathrm{mg} /$ day and treatment duration was 3.5 years (18). These treatment parameters are greater than those from most other studies, thus possibly leading to an increase in major hemorrhagic events in the results.

Combining Clop + ASA is a potent antiplatelet therapy. Therefore, it is necessary to balance their therapeutic effects with potential hemorrhagic risks to optimize the benefits for patients. The results suggest that taking Clop + ASA early appears to be a safe and effective therapy for TIA/minor stroke patients. We believe that the ongoing POINT study (22) in the United States and other similar studies may provide evidence to support our hypothesis in the future.

This study has the following limitations: i) because of the limited amount of research in this field, this meta-analysis only included five studies, therefore, it is difficult to make reliable conclusions; ii) only TIA/minor stroke patients and Clop + ASA vs. ASA therapy are included, and as a result, the narrow scope may have an impact on the conclusion from extrapolation; iii) among patients in the included studies, between the onset of symptoms to inclusion in their respective studies occurred at various time points. Start time for treatment ranged from $24 \mathrm{~h}$ to 3 months after initial symptoms. Early treatment can lead to improved prognosis. Thus, the differences in start time of treatment between the studies may affect the final treatment effect; and iv) the dosages of Clop + ASA and treatment times in the included studies were highly variable. Since higher doses of Clop + ASA given for prolonged periods of time increase the risk of bleeding complications, the wide range may contribute to differences in results between our study and others.

In conclusion, future research should focus on determining: i) whether Clop + ASA therapy is also suitable for other types of ischemic stroke; ii) an appropriate treatment window for TIA/minor stroke patients with Clop + ASA; and iii) the optimal treatment dosage and duration of Clop + ASA for patients with a recent TIA/minor stroke. Future largescale clinical trials may provide answers to these questions and guide evidence-based approaches for the treatment of this disease.

\section{Acknowledgements}

This study was supported by Research and Development Project of Xiangyang in 2013 (no. 201302) and Scientific
Research Project of Hubei Provincial Department of Education in 2014 (B2014051).

\section{References}

1. Johnston SC, Fayad PB, Gorelick PB, Hanley DF, Shwayder P, van Husen D and Weiskopf T: Prevalence and knowledge of transient ischemic attack among US adults. Neurology 60: 1429-1434, 2003.

2. Wang YL, Wu D, Liao X, Zhang W, Zhao X and Wang YJ: Burden of stroke in China. Int J Stroke 2: 211-213, 2007.

3. Zhao D, Liu J, Wang W, Zeng Z, Cheng J, Liu J, Sun J and Wu Z: Epidemiological transition of stroke in China: Twenty-one-year observational study from the Sino-MONICA-Beijing Project. Stroke 39: 1668-1674, 2008.

4. Edlow JA, Kim S, Pelletier AJ and Camargo CA Jr: National study on emergency department visits for transient ischemic attack, 1992-2001. Acad Emerg Med 13: 666-672, 2006.

5. Rothwell PM, Giles MF, Chandratheva A, Marquardt L, Geraghty O, Redgrave JN, Lovelock CE, Binney LE, Bull LM, Cuthbertson FC, et al: Effect of urgent treatment of transient ischaemic attack and minor stroke on early recurrent stroke (EXPRESS study): A prospective population-based sequential comparison. Lancet 370: 1432-1442, 2007.

6. Luengo-Fernandez R, Gray AM and Rothwell PM: Effect of urgent treatment for transient ischaemic attack and minor stroke on disability and hospital costs (EXPRESS study): A prospective population-based sequential comparison. Lancet Neurol 8: 235-243, 2009.

7. Jauch EC, Saver JL, Adams HP Jr, Bruno A, Connors JJ, Demaerschalk BM, Khatri P, McMullan PW Jr, Qureshi AI, Rosenfield K, et al; American Heart Association Stroke Council; Council on Cardiovascular Nursing; Council on Peripheral Vascular Disease; Council on Clinical Cardiology: Guidelines for the early management of patients with acute ischemic stroke: A guideline for healthcare professionals from the American Heart Association/American Stroke Association. Stroke 44: 870-947, 2013.

8. Hankey GJ and Eikelboom JW: Antithrombotic drugs for patients with ischaemic stroke and transient ischaemic attack to prevent recurrent major vascular events. Lancet Neurol 9: 273-284, 2010

9. Moher D, Liberati A, Tetzlaff J and Altman DG; PRISMA Group: Preferred reporting items for systematic reviews and meta-analyses: The PRISMA statement. BMJ 339: b2535, 2009.

10. Higgins JPT and Green S (eds): Cochrane Handbook for Systematic Reviews of Interventions Version 5.1.0. [updated March 2011]. The Cochrane Collaboration, 2011.

11. Guyatt GH, Oxman AD, Vist GE, Kunz R, Falck-Ytter Y, Alonso-Coello $P$ and Schünemann HJ; GRADE Working Group: GRADE: An emerging consensus on rating quality of evidence and strength of recommendations. BMJ 336: 924-926, 2008.

12. Higgins JP and Thompson SG: Quantifying heterogeneity in a meta-analysis. Stat Med 21: 1539-1558, 2002.

13. Egger M, Davey Smith G, Schneider M and Minder C: Bias in meta-analysis detected by a simple, graphical test. BMJ 315 : 629-634, 1997.

14. Wang Y, Wang Y, Zhao X, Liu L, Wang D, Wang C, Wang C, Li H, Meng X, Cui L, et al; CHANCE investigators: Clopidogrel with aspirin in acute minor stroke or transient ischemic attack. N Engl J Med 369: 11-19, 2013.

15. Kennedy J, Hill MD, Ryckborst KJ, Eliasziw M, Demchuk AM and Buchan AM; FASTER Investigators: Fast assessment of stroke and transient ischaemic attack to prevent early recurrence (FASTER): A randomised controlled pilot trial. Lancet Neurol 6: 961-969, 2007.

16. Markus HS, Droste DW, Kaps M, Larrue V, Lees KR, Siebler M and Ringelstein EB: Dual antiplatelet therapy with clopidogrel and aspirin in symptomatic carotid stenosis evaluated using doppler embolic signal detection: The Clopidogrel and Aspirin for Reduction of Emboli in Symptomatic Carotid Stenosis (CARESS) trial. Circulation 111: 2233-2240, 2005.

17. Côté R, Zhang Y, Hart RG, McClure LA, Anderson DC, Talbert RL and Benavente OR: ASA failure: Does the combination ASA/clopidogrel confer better long-term vascular protection? Neurology 82: 382-389, 2014. 
18. Benavente OR, Hart RG, McClure LA, Szychowski JM, Coffey CS and Pearce LA; SPS3 Investigators: Effects of clopidogrel added to aspirin in patients with recent lacunar stroke. N Engl J Med 367: 817-825, 2012.

19. Geeganage CM, Diener HC, Algra A, Chen C, Topol EJ, Dengler R, Markus HS, Bath MW and Bath PM; Acute Antiplatelet Stroke Trialists Collaboration: Dual or mono antiplatelet therapy for patients with acute ischemic stroke or transient ischemic attack: Systematic review and meta-analysis of randomized controlled trials. Stroke 43: 1058-1066, 2012.

20. Palacio S, Hart RG, Pearce LA and Benavente OR: Effect of addition of clopidogrel to aspirin on mortality: Systematic review of randomized trials. Stroke 43: 2157-2162, 2012.
21. Wong KS, Chen $\mathrm{C}, \mathrm{Fu}$ J, Chang HM, Suwanwela NC, Huang YN, Han Z, Tan KS, Ratanakorn D, Chollate P, et al; CLAIR study investigators: Clopidogrel plus aspirin versus aspirin alone for reducing embolisation in patients with acute symptomatic cerebral or carotid artery stenosis (CLAIR study): A randomised, open-label, blinded-endpoint trial. Lancet Neurol 9: 489-497, 2010.

22. Johnston SC, Easton JD, Farrant M, Barsan W, Battenhouse H, Conwit R, Dillon C, Elm J, Lindblad A, Morgenstern L, et al: Platelet-oriented inhibition in new TIA and minor ischemic stroke (POINT) trial: Rationale and design. Int J Stroke 8: 479-483, 2013. 